\title{
田
}

\section{CONSERVADORISMO, BANCO MUNDIAL E SERVIÇO SOCIAL: O (NEO) DESENVOLVIMENTISMO E AS REFORMAS SOCIAIS}

\author{
Conservatives, World Bank and social service: (neo) development and social reforms
}

\section{Ana Cristina Oliveira de Oliveira* (c) (†)}

\section{RESUMO}

Este artigo revela os resultados parciais de uma pesquisa documental que estuda a nova sociabilidade do capital e suas manifestações a partir dos anos 2000, tendo como norteador as estratégias de desenvolvimento no combate à pobreza. O texto discute os processos potenciados pelas políticas neoliberais-(neo)desenvolvimentistas que resgatam o reformismo social e o conservadorismo edificando um pensamento único na contramão da construção do projeto ético político profissional. Trata, ainda, da investida do Banco Mundial como um interlocutor direto na ação política e econômica nos países de capitalismo dependente. Entende que a abordagem do conservadorismo se apresenta na ação política de direita já consolidado no passado e que não se apresenta como algo novo. Entende que é constitutiva da dinâmica do capital e do tratamento na relação entre a acumulação do capital e seus impactos na força viva de trabalho. Concluímos que a defesa das reformas sociais implica na roupagem mais humana do capitalismo e na retomada do conservadorismo na profissão. E que neste sentido, o Serviço Social enfrenta o desafio de aproximar-se dos movimentos sociais organizados no horizonte da organização da classe trabalhadora para a contra-ordem burguesa e a desnaturalização da "questão social".

\section{PALAVRAS-CHAVE}

Pobreza. Reformas sociais. Conservadorismo. Banco Mundial. Serviço Social.

\section{ABSTRACT}

This article reveals the partial results of a documentary research that studies the new sociability of capital and its manifestations from the years 2000, having as guiding the strategies of development in the fight against poverty. The text discusses the processes fostered by neoliberal-(neo) developmentalist policies that rescue social reformism and conservatism by building a unique thought against the construction of the professional political ethical project. It also refers to the World Bank as a direct interlocutor in political and economic action in dependent capitalist countries. It considers that the approach of conservatism is presented in the political action of right already consolidated in the past

\footnotetext{
* Assistente Social. Doutora em Serviço Social (UERJ). Professora da Escola de Serviço Social da Universidade Federal Fluminense. Rua Miguel de Frias, 9, Icaraí, Niterói (RJ), CEP.: 24220-900. E-mail: <anacoliveira6o@gmail.com>.ORCID: <https://orcid.org/0000-0002-3806-6385>.
}

Temporalis, Brasília (DF), ano 18, n. 35, jan./jun. 2018. 


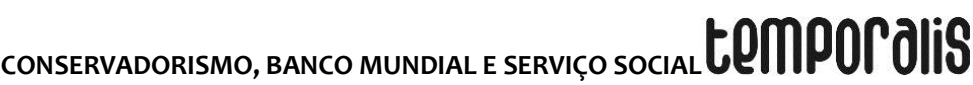

and that does not appear like something new. It understands that it is constitutive of the dynamics of capital and of the treatment in the relation between the accumulation of capital and its impacts on the living labor force. We conclude that the defense of social reforms implies the more human dress of capitalism and the resumption of conservatism in the profession. In this sense, Social Service faces the challenge of approaching the organized social movements in the horizon of the organization of the working class for the bourgeois counter-order and the denaturalization of the "social question".

\section{KEYWORDS}

Poverty. Social reforms. Conservatism. The World Bank. Social work.

Submetido em: 4/5/2018.

Aceito em: 7/6/2018.

\section{INTRODUÇÃO}

Em nome da defesa do mercado e do capital vivemos uma crise estrutural do capital (MESZÀROS, 2011; CARCANHOLO, 2011) sem precedentes no campo econômico, político, social e ideológico cujo reino pretende-se à acumulação cada vez maior com base na propriedade dos meios de produção e trabalho alheio. Nos últimos anos esta crise tem sido sustentada pela regressão dos direitos e destruição do legado de conquistas históricas dos trabalhadores.

Diante do cenário atual, intencionamos trazer alguns elementos preliminares de como o conservadorismo dominante assola as pretensões sociais de fortalecimento da superação da superexploração da força de trabalho1. A ênfase se dá na presença na perda histórica de direitos sociais conquistados no processo de luta de classes no bojo da redemocratização brasileira. Neste momento está em risco a manutenção da democracia política no país.

O objetivo do artigo é contribuir para a discussão dos processos potenciados pelas políticas neoliberais e (neo) desenvolvimentistas que resgatam o reformismo político e o conservadorismo da moralização da questão social que edificam um constructo de pensamento único na contramão do projeto ético político profissional. Cabe considerar que, no interior do Serviço Social, tem sido reproduzido o conservadorismo desafiando o princípio do projeto ético-político da profissão.

O atual momento de disputa na luta de classe tem como pano de fundo o crescimento de um reacionarismo conservador de extrema direita que remonta uma política externa subserviente e alinhada com os interesses do capitalismo internacional dominante.

Compreendemos que o Assistente Social, como classe trabalhadora (IAMAMOTO, 1999), não pode ficar alheio à abordagem dos poderes imperialistas num cenário de intensificação da investida contra a organização coletiva de todos aqueles que,

\footnotetext{
1 A categoria da superexploração da força de trabalho foi elaborada por Ruy Mauro Marini como fundamento da teoria marxista da dependência (TMD). Segundo Marini (2005) na superexploração da força de trabalho, o trabalho é remunerado abaixo do seu valor por serem negados ao trabalhador as condições necessárias para repor o desgaste de sua força de trabalho, estimulando o seu esgotamento antecipado. Ver Marini (2005); Luce (2011; 2012; 2018) e Osorio (2009; 2013).
}

Temporalis, Brasília (DF), ano 18, n. 35, jan./jun. 2018. 


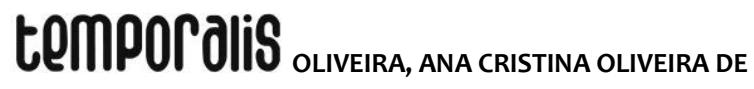

destituídos da propriedade, dependem de um lugar nesse mercado, cada dia, mas restrito e seletivo, que lhes permita produzir o equivalente de seus meios de vida. Assim como, não ficarem alheios à investida do conservadorismo reacionário que alavanca com resultados recentes antidemocráticos, antipopular e antiprogressistas na investida de pensadores e intelectuais vinculados às tradições - teóricas e políticas - do pensamento conservador que vem conduzindo um rumo no mundo à direita (CUEVA, 1989 apud NETTO, 2011).

Cada vez mais o Brasil tem se tornado emblemático no jogo político-econômico entre os países de capitalismo dependente, considerado liderança política e econômica da região. Assim como, é o elo entre a integração latino-americana, o fortalecimento das relações Sul-Sul, tendo suas relações para além do continente. A relevância do país nas suas relações internacionais, em anos recentes, é revelada pela aliança entre os países latinoamericanos e os BRICS², cujo principal logro foi a criação do Acordo de Reservas de Contingência e o Banco de Desenvolvimento dos BRICS-Celac ${ }^{3}$. Antes de tudo, este elemento tem como um dos objetivos dessas instituições o financiamento de programas de infraestrutura e desenvolvimento na região, como alternativa ao financiamento predatório realizado pelo Fundo de Monetário Internacional (FMI) e o Banco Mundial.

\section{(NEO) DESENVOLVIMENTO e BANCO MUNDIAL: estratégias de gerenciamento da pobreza}

Em um relatório intitulado Por que menos desigualdade beneficia a todos, a OCDE destaca que "[...] a diferença entre ricos e pobres nunca esteve tão alta" (ORGANIZAÇÃO PARA A COOPERAÇÃO E DESENVOLVIMENTO ECONÓMICO, 2018). O ano de 2015 tem uma marca histórica de concentração de riqueza mundial de $1 \%$ da população mundial, onde alcançou a metade do valor total de ativos. "Em outras palavras: $1 \%$ da população mundial, aqueles que têm um patrimônio avaliado em 760.000 dólares (2,96 milhões de reais), possuem tanto dinheiro líquido e investido quanto o 99\% restante da população mundial" (FARIZA, 2015, não paginado).

Essa elevada disparidade de desigualdade social onde os ricos sairão da crise sendo mais ricos, e os pobres, relativamente mais pobres tem sua gênese na acumulação primitiva que adensa no território brasileiro como um dos centros de acumulação de capital. Entretanto, é preciso considerar que o Brasil avança na posição sub-imperialista na produção e transferência de valor excedente de produção pela via do comércio legitimando a superexploração da força de trabalho.

\footnotetext{
${ }^{2}$ BRICS é o nome de um conjunto econômico de países considerados emergentes, formado atualmente pelo Brasil, Rússia, Índia, China e África do Sul.

${ }^{3}$ A Cúpula da Comunidade dos Estados Latino-americanos e Caribenhos (Celac)foi fundada em Caracas no final de 2011 como contraponto à Organização dos Estados Americanos (OEA) incluindo Cuba no quadro de sócios dominados pelos norte-americanos. A Celac reúne 33 países americanos, não admitindo representantes dos EUA e Canadá e propugna a integração soberana e democrática dos países que compõem a comunidade (MARTINS, 2014, não paginado).

4 Organização para a Cooperação e Desenvolvimento Económico (OCDE). Criada em 1948, a OCDE é uma organização internacional composta por 34 países que aceitam os princípios da democracia representativa e da economia de livre mercado. Tem como objetivo principal fornecer uma plataforma para comparar políticas econômicas, solucionar problemas comuns e coordenar políticas domésticas e internacionais.
}

Temporalis, Brasília (DF), ano 18, n. 35, jan./jun. 2018. 


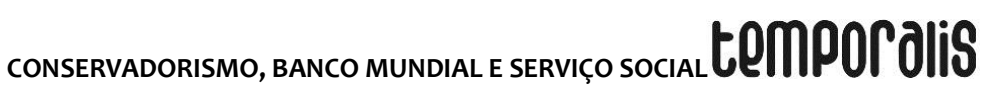

Conforme tratado por Marini o interesse nos seus estudos era contribuir com o estudo das "[...] leis de desenvolvimento do capitalismo dependente" (MARINI, 2005, 181). A superexploração tradada por Marini é revelada pelo próprio Marx no início das Teorias da Mais-Valia onde refere que a essência da dependência é a transferência de valor: "Porque hay transferencia de plusvalor de un capital global nacional menos desarrollado hacia el que es más desarrollado, y ésta es la esencia o fundamento de la dependencia (diría Marx), es necesario compensar dicha pérdida extrayendo más plusvalor al trabajo vivo periférico" (DUSSEL, 1988 apud LEITE, 2015, p. 33-34).

Para Marini (LUCE, 2011) o subimperialismo tem sua origem nas leis próprias da economia dependente, cujos fundamentos são a superexploração do trabalho e a transferência de valor. É um fenômeno que pode ser apreendido através da combinação de quatro variáveis: grau de monopolização e de operação do capital financeiro na economia dependente, a mobilização de um esquema particular de realização do capital (Estado, mercado externo e consumo suntuário ${ }^{5}$ ), hegemonia em um subsistema regional de poder, lógica da cooperação antagônica com o imperialismo dominante.

Com a mistificação inerente ao capital, enquanto relação social alienada que monopoliza "[...] os frutos do trabalho coletivo obscurece a fonte criadora que anima o processo de acumulação em uma escala exponencial no cenário mundial: o universo do trabalho." (IAMAMOTO, 2006, p. 161). Intensifica-se a investida contra a organização coletiva de todos aqueles que, destituídos da propriedade, dependem de um lugar nesse mercado, cada dia, mas restrito e seletivo, que Ihes permita produzir o equivalente de seus meios de vida. Com isso, crescem as desigualdades sociais de classe. Esses processos são potenciados pelas políticas neoliberais - (neo) desenvolvimentistas, que "[...] capturam os estados nacionais, erigidas pelos poderes imperialistas como caminho único para animar o crescimento econômico, cujo ônus recai sobre as grandes maiorias" (IAMAMOTO, 2006, p. 162).

Aqui abrimos um diálogo para a compreensão de que não se trata de algo novo. A retomada do desenvolvimentismo sob uma nova roupagem tem acento numa nova estratégia de desenvolvimento (o neodesenvolvimentismo) que se assenta no início dos anos 2000, com a participação intensa do economista Luiz Carlos Bresser-Pereira6.

A partir deste ponto de vista, diversos autores consideram o (neo) desenvolvimentismo como se fosse uma estratégia alternativa ao neoliberalismo calcado na economia heterodoxa e que parte da esquerda absorve como campo de luta (OLIVEIRA, 2012).

Longe de ser uma proposta verdadeiramente nova, o novo-desenvolvimentismo de Bresser-Pereira reeditava um diagnóstico elaborado por neoestruturalistas e economistas heterodoxos (de tradições diversas) nos vinte anos anteriores. (BONENTE; CORRÊA, 2015, p. 112).

\footnotetext{
5 Luce (2011) aponta a compreensão que Marini tem sobre o consumo suntuário. Para Marini o "[...] consumo suntuário é constituído pelo mercado de bens de luxo em contraste com o mercado de bens de consumo que fazem parte do consumo corrente dos trabalhadores" (LUCE, 2011, p. 118-119). O consumo em que a classe trabalhadora não tem acesso.

${ }^{6}$ Para maiores interlocuções, chamamos a atenção para os autores Bonente (2011), Castelo (2012), Oliveira (2012) e Sampaio Júnior (2012), Bonente e Corrêa (2015) como alguns exemplos.
}

Temporalis, Brasília (DF), ano 18, n. 35, jan./jun. 2018. 


\title{
tempordilis o

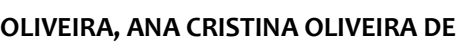

Em contrapartida temos pesquisas que avançam no diálogo com esta positividade que revela que o (neo) desenvolvimentismo trata-se se uma roupagem do neoliberalismo.

\begin{abstract}
Como ponto de partida da proposta novo-desenvolvimentista, encontra-se o diagnóstico de que as políticas econômicas amparadas pelo receituário neoliberal não eram políticas focadas na promoção do desenvolvimento e que, diante do cenário atual, a retomada do desenvolvimento faz-se imperativa. Por outro lado, a proposta não se resume ao simples resgate do velho desenvolvimentismo, considerado obsoleto $e$ inadequado à realidade contemporânea (BONENTE; CORRÊA, 2015, p. 111).
\end{abstract}

Transformações históricas alteraram a face do capitalismo, nos países centrais, em particular, na América Latina. Tendo um longo período de crise da economia mundial, o capitalismo avançou em sua vocação de internacionalizar a produção e os mercados, requerendo políticas de ajustes estruturais por parte dos países de capitalismo dependente (MÉSZAROS, 2011). Estas políticas dão livre acesso ao capital especulativo financeiro destituído de regulamentações e a lucratividade dos grandes conglomerados multinacionais, sendo preconizadas pelos países imperiais por intermédio dos organismos multilaterais (BORÓN, 1995).

Através de análise da pesquisa documental sobre os documentos das Estratégias de Assistência ao País (EAPs), 2003, do Banco Mundial ao Governo Brasileiro, indicamos que o Banco Mundial é um norteador das estratégias de desenvolvimento no combate à pobreza. Neste contexto, a pesquisa ao analisar a construção de um novo consenso social das classes subalternas pela concepção do mundo da burguesia sobre a "questão social", identifica o Banco Mundial como parte das corporações capitalistas de uma prática e ideologia favorável à acumulação capitalista, ainda que indique a erradicação da pobreza. Neste movimento revela um conflito na disputa ideológica ao ser absorvida como uma proposta progressista no enfrentamento da questão social ao coadunar com a ideologia (neo) desenvolvimentista (OLIVEIRA, 2012).

O Banco Mundial vem se apresentando como um dos intelectuais da nova pedagogia da hegemonia (NEVES, 2005). Parte da comprovação de que a expressão da contrahegemonia permanece no século XXI o seu significado numa relação direta com a ideia de desenvolvimento (sustentável) para a democratização associada a uma possível nova hegemonia vem sendo regida sob a égide dos rosários dos neo e de um capital mais humano (OLIVEIRA, 2012).

O novo consenso acaba por reforçar o redirecionamento das esferas pública e privada na prestação de serviços sociais. Em especial, recuperar o debate da centralidade da dependência na América Latina, enquanto categoria que explica o real movimento do capital no continente ao longo dos processos históricos que revelam o inerente desenvolvimento desigual e combinado característico do capitalismo dependente. Entender este movimento supõe a historicidade do ator político, intelectual e financeiro (PEREIRA, 2010) que atravessam as políticas públicas dos países de capitalismo dependente. 


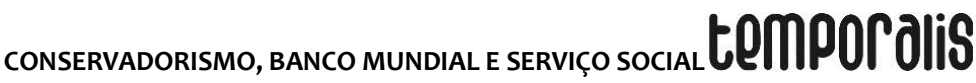

No cenário pós Consenso de Washington (1989), o Estado tem sua atuação redimensionada, em que interviria em prol do cumprimento dessas medidas deliberadas. Ou seja, um Estado que se propõe a garantir um clima de investimento de mercado favorável e assegure políticas focalizadas - reduzindo os gastos do Estado em políticas sociais - para o gerenciamento da pobreza. O segundo período de ajuste teve início a partir dos anos 2000 (em especial com a Política de Desenvolvimento do Milênio/Organização das Nações Unidas7), defendida pelos organismos internacionais como Banco Mundial e FMI, uma ideologia de humanização, em que pautada nos princípios da equidade promovem um novo caráter para a universalidade ao acesso de políticas sociais. Além da defesa de que para obter o desenvolvimento dos países deve-se haver uma necessidade de combate à pobreza concomitantemente. Com este legado, ocorre uma centralização da pobreza nas políticas sociais.

Esta nova visão de estratégias para gerenciamento da pobreza foi difundida em documentos do Banco Mundial neste período do segundo ajuste neoliberal. O Relatório sobre o Desenvolvimento Mundial de 2005 Equidade e Desenvolvimento aborda esse princípio da equidade que orienta a lógica de humanização dessa geração de ajuste. Segundo o documento, a equidade é estabelecida a partir de dois termos principais. A teoria oportunidades iguais, em que fatores culturais, étnicos, de gênero, sociais e familiar não poderiam definir as possibilidades de conquistas dos sujeitos. Os indivíduos devem por meio de sua capacidade, esforço e talento definir suas conquistas e para isso precisam de condições melhores de vida.

O segundo é a prevenção de privação de resultados, em que o direito deve ser garantido das pessoas terem oportunidades iguais para alcançarem os objetivos que almejam e fugir da privação de resultados. Por isso, o relatório faz uma articulação entre equidade e prosperidade. Em uma sociedade em que todos possuem as mesmas oportunidades, tanto políticas, sociais e econômicas condicionam um crescimento e desenvolvimento saudáveis. Assim, é repassada a face mais humana dessa geração de ajustes, com ilustração de um princípio de equidade como forma de controle social e manutenção e reprodução da ideologia neoliberal.

A pobreza, aqui entendida como pauperismo, é uma resultante do processo de acumulação do capital e assume novos significados no movimento sócio-histórico trazendo hoje novas determinações e contradições para sua compreensão e combate. Este contexto ganha voz nos organismos multilaterais e instituições financeiras internacionais.

Recuperamos, portanto, a tese de Karl Marx expressa na Lei Geral da Acumulação Capitalista e a formação da superpopulação relativa. Na demanda da compreensão sobre os fundamentos do (neo) desenvolvimentismo e o levante da "questão social" (IAMAMOTO, 2003; 2006).

Pretende-se, neste sentido, retomar a categoria classe e luta de classes na tentativa de expurgar o tratamento da "questão social" como coisa e algo natural. Pretendemos,

\footnotetext{
${ }^{7}$ A Política de Desenvolvimento do Milênio foi definida pela Cúpula do Milênio da Organização das Nações Unidas, realizado em 2000, em Nova York.
}

Temporalis, Brasília (DF), ano 18, n. 35, jan./jun. 2018. 


\section{temporalis}

ainda, discutir a investida neoliberal no gerenciamento da "questão social", tendo o "terceiro setor" como protagonista. Conclama-se, portanto, a importância da compreensão sobre a forma como se dá a difusão ideológica dos agentes do capital a partir da categoria ideologia e hegemonia na perspectiva marxiana.

\section{BANCO MUNDIAL e MUNDIALIZAÇÃO DO CAPITAL: mecanismos hegemônicos}

As transformações no mundo do trabalho no contexto da mundialização do capital ${ }^{8}$ (CHESNAIS, 1996) e as implicações sobre a "questão social", segundo lamamoto (2008), assumem expressões particulares no avanço de sua "[...] vocação de internacionalizar a produção e os mercados [...]" (lamamoto, 2008, p. 118), aprofundando a desigualdade entre países "[...] e, no seu interior, entre classes e grupos sociais no âmago das relações dialéticas entre imperialismo e dependência" (IAMAMOTO, 2008, p. 118).

O que vale destacar, neste cenário de mudanças, é a atuação da contratendência política e ideológica é pautada na nova questão social a partir da crise que o sistema capitalista internacional enfrenta. Este é agravado pelo esgotamento do modelo fordistakeynesiano vigorado até os anos 1970 e reforçado pela queda do mundo socialista.

No debate sobre pobreza (demarcada amplamente na contemporaneidade) e a desigualdade social, alguns debatedores (pensadores sociais que propagam um novo paradigma de políticas sociais) defendem uma "nova questão social" com base nas mudanças ocorridas no mundo capitalista. Anunciam uma ruptura com o período industrial e com a "questão social" originária na primeira metade do século XIX, a partir do surgimento do pauperismo, na Europa Ocidental.

Entendemos que esta compreensão sobre as manifestações da "questão social" na contemporaneidade devem ser tidas como algo imprescindível ao desenvolvimento tecnológico. E não na naturalização dessas manifestações. Nestes termos, a mundialização do capitalismo financeiro ${ }^{9}$ não pode ser naturalizada, por representar um produto da estratégia norte-americana (imperialista) de controle quase absoluto da economia mundial capitalista à lógica financeira.

A mundialização do capital financeiro imposto pelos Estados Unidos (EUA) obriga "[...] o restante do mundo capitalista a liberalizar os fluxos internacionais de capital (a chamada

\footnotetext{
${ }^{8} \mathrm{O}$ termo de origem francesa (mondialisation) mundialização do capital é desenvolvido por François Chesnais no livro A mundialização do capital (1996) onde trabalha com a desmistificação da natureza da globalização propagada pelo neoliberalismo para a integração internacional dos mercados financeiros. Esta integração internacional leva à abertura dos mercados nacionais e permite sua interligação em tempo real da regulação e da liberalização. A expressão mundialização do capital revela que a globalização são "[...] operações de arbitragem feitas pelos mais importantes e mais internacionalizados gestionários de carteiras ativos, cujo resultado decide a integração ou exclusão em relação as benesses das finanças de mercado" (CHESNAIS, 1996, p. 17 e 25, grifo do autor).

${ }^{9} \mathrm{O}$ evento da globalização financeira nos marcos da ruptura com o padrão monetário dólar-ouro (sistema Bretton Woods) foi acelerado por "[...] um conjunto de políticas deliberadas pelos EUA, a partir da forte reversão da liquidez internacional em sua direção, iniciada em fins de 1979 como resultado da diplomacia do dólar" (TAVARES ; MELIN, 1998, p. 43).
}

Temporalis, Brasília (DF), ano 18, n. 35, jan./jun. 2018. 


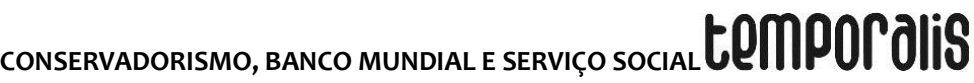

desregulação financeira) e a financiar as crescentes dívidas pública e externa dos EUA". (TAVARES; MELIN, 1998, p. 43).

Vejamos como se dá a maquinaria da "nova" engenharia do bloco social hegemônico dominante. O que ocorre é que na mundialização do capital os organismos multilaterais conduzem os

\begin{abstract}
Estados nacionais e o espaço mundial, atribuindo um caráter cosmopolita à produção e consumo de todos os países; e simultaneamente, radicaliza o desenvolvimento desigual e combinado, que estrutura as relações de dependência entre nações no cenário internacional (IAMAMOTO, 2007, p. 107).
\end{abstract}

Este contexto é caracterizado "[...] pelos grandes grupos industriais transnacionais articulado ao mundo das finanças" (IAMAMOTO, 2007, p. 107). O bloco social dominante aciona os organismos internacionais, em destaque o Banco Mundial, para conduzir a "questão social" através políticas sociais pontuais, fragmentadas e assistencialistas no processo de expansão imperialista.

É diante desse conjunto de questões que se propõe observar o Banco Mundial como propulsor de ações para a erradicação da pobreza em todo o mundo, através de políticas sociais cada vez mais focalizadas (OLIVEIRA, 2012).

O foco principal do Banco Mundial é o combate à pobreza. Erradicar a pobreza extrema no mundo é a sua meta, trabalhando na lógica atual, que a pobreza extrema é medida por pessoas que vivem com a renda menor de $\$ 1,25$ (dólar) por dia, como retratado no seu Relatório sobre o Desenvolvimento Mundial do ano de 2013.

A mudança radical que o mundo passa, exige que o BM assuma o compromisso de acompanhar esse desenvolvimento com seu foco na pobreza. Cerca de 1,2 bilhão, segundo dados do próprio Banco (BANCO MUNDIAL, 2013) vivem em pobreza extrema, o alcance do objetivo de erradicar a extrema pobreza, tendo vem vista que a renda não é o fator primordial de modificação para alterar a condição de pobreza.

Dentro dos objetivos de enfrentamento à pobreza, o Banco Mundial segue duas linhas de intervenção: erradicar a pobreza extrema e a promoção da prosperidade compartilhada (BANCO MUNDIAL, 2013). A promoção da prosperidade, contida no documento, é o incentivo ao aumento da renda. Para alcançar esse objetivo é necessário estimular a melhora do padrão de vida de extrema pobreza e dar oportunidades para eles saírem dessa condição.

O capitalismo promove a pobreza, a desigualdade, pois sua lógica de acumulação só é permitida graças a essa contradição. Assim, é claramente observável que as medidas tomadas pelo Banco Mundial no combate a extrema pobreza são inválidas. As formas de combate à pobreza promovida pelo Banco Mundial não faz mais do que reproduzi-las na lógica de ampliação da acumulação de capital. Portanto, nenhuma das ações promovidas pelo Banco Mundial irá em direção contrária da redução da desigualdade social, ou ainda sua eliminação, já que suas intervenções são condicionadas em defesa do grande capital.

Temporalis, Brasília (DF), ano 18, n. 35, jan./jun. 2018. 


\section{temporalis}

Assim, o Banco Mundial assume o caráter de difusor ideológico da nova pedagogia da hegemonia (NEVES, 2005) e considera que a construção de um capitalismo mais humano garantiria maior coesão social e, para além deste horizonte, seria a chave do desenvolvimento. A meta do Banco Mundial é de "[...] apoiar as principais reformas de políticas e investimentos inovadores e eficientes, com o objetivo de aumentar o bemestar dos brasileiros, em particular dos pobres" (BANCO MUNDIAL, 2003, p. 11).

Com esta direção, o capitalismo mais humano realiza a promoção da autoestima, resgatando valores grupais, para constituir aspectos culturais com base de assimilação de uma política de desenvolvimento autossustentado. Estes valores foram a base de definição de políticas econômicas de determinados economistas do atual quadro do governo federal com a Presidenta Dilma Rousseff (2011) e nas duas gestões do governo anterior do presidente Luiz Inácio Lula da Silva, entre primeiro de janeiro de 2003 a 2016.

Este remete a ideia de um neoliberalismo vendido como mais humano para manter a coesão social e dar condições de reprodução à política econômica e à ideologia neoliberal na crise estrutural da classe dominante. Nesta direção, privilegiamos a identificação dos mecanismos hegemônicos e a direção intelectual e moral contidos nestas políticas.

\section{(NEO) CONSERVADORISMO, POBREZA E A AGENDA REFORMISTA}

A reconfiguração do trabalho na sociedade contemporânea, por meio do processo de reestruturação, produziu a intensificação da exploração da força de trabalho. Exigi-se um trabalhador polivalente e flexível que trabalha em condições precárias como os terceirizados, sem estabilidade no emprego, com contratações precárias e informais.

A flexibilização das formas de contratação resultam na desterritorialização onde agora o trabalhador não está diretamente ligado a um só espaço de trabalho, como antes no ambiente fabril. Agora ele pode estar desempenhando sua atividade fora do ambiente de trabalho de quem demanda seus serviços, há um número menor de trabalhadores agora, que coordenam várias máquinas. O uso da tecnologia se amplia e diversos trabalhadores vão perdendo seus postos de trabalho, acarretando no desemprego estrutural. Essas formas de trabalho consequentemente afetam as organizações dos trabalhadores, que encontram dificuldades em se organizarem.

O capitalismo se apropria da subjetividade do trabalhador, cria uma lógica de competitividade, na qual o trabalhador tem que estar a todo momento investindo na sua educação e qualificação voltados para o mercado e não para a emancipação humana.

Um mundo internacionalizado requer um Estado dócil aos influxos neoliberais, mas ao mesmo tempo forte internamente - ao contrário do que é propalado pelo ideário neoliberal da minimização do Estado - para traduzir essas demandas em políticas nacionais e resistir à oposição e protestos de muitos, comprometendo a soberania das nações (PETRAS, 2002).

A nova fase do imperialismo supõe-se, portanto, que não há novidade na estrutura do capital e de que nada mais é do que uma nova roupagem do conservadorismo ascendida na guinada do milênio (OLIVEIRA, 2013). Em especial no Brasil, cuja inserção na nova divisão internacional do trabalho deu-se aprofundando seu caráter capitalista

Temporalis, Brasília (DF), ano 18, n. 35, jan./jun. 2018. 


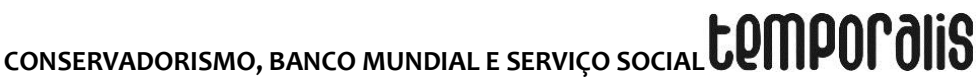

dependente, consonante com uma pretensa condução de políticas públicas humanizantes, focadas no alívio da pobreza e na geração de renda, esvaziando o sentido político para a consolidação da garantia de direitos sociais previstas na Constituição Cidadã (1988). Trata-se da batalha de ideias, mais especificamente do processo de hegemonia pelo qual a classe dominante se conserva, criando novos terrenos ideológicos na disputa de classe.

De acordo com Oliveira (2013) o esgotamento do neoliberalismo, nos anos 1990, por mais de vinte anos sustentou um modelo de subordinação da América Latina à nova fase imperialista do grande capital, de caráter espoliativo, dependente do modo de produção capitalista na região. As promessas neoliberais não foram cumpridas com o aumento da desigualdade econômica, social e cultural.

A inserção do Brasil no sistema global, assim como outros Países em Desenvolvimento (BANCO MUNDIAL, 2003), numa explícita disputa no terreno intelectual, político e econômico, se traduzia no confronto da produção de desigualdades com a aceleração do crescimento da pobreza e na garantia de um ambiente seguro econômico pela estabilidade macroeconômica pelos organismos internacionais, em especial o Banco Mundial.

Conforme Yazbek (1993) “[...] o resultado do campo das políticas públicas na área social, na América Latina, tem sido reforço de traços de improvisação e inoperância, o funcionamento ambíguo e sua impotência na universalização doa acesso aos serviços dela derivados" (YAZBEK, 1993, p. 37). Permanecem políticas casuísticas e fragmentadas, sem regras estáveis e operando em redes públicas obsoletas e deterioradas. Acrescentamos a este debate com a autora que a intervenção junto às políticas públicas na área social revela a Lei Geral de Acumulação do Capital (MARX, 1996) com interesses coadunados com o capital internacional sob as orientações, por assessoria técnica e empréstimo, aos países de capitalismo dependente.

A nova engenharia do bloco social associada ao argumento de uma nova questão social indica-nos a necessidade de compreensão sobre o fenômeno questão social, historicamente determinado e tratado de forma reduzida, como um problema de pobreza.

Sabe-se que a pobreza e a desigualdade social são fenômenos sociais que perpassam diversas sociedades ao logo da história e que "[...] a pobreza e a caridade são marcadas por um valor positivo que o cristianismo deu à renúncia dos bens do mundo [...]" (MARTINELLI, 2004, p. 29) durante a Idade Média ${ }^{10}$, "[...] considerando que Pauperitas et humilitas são indispensáveis um do outro" (MARTINELLI, 2004, p. 29).

\footnotetext{
10 Dividida em três classes: clero, nobreza e povo a Idade Média, na cronologia européia, inicia-se com a queda do Império Romano do Ocidente, em 476 d.c. Marcada pela ruralização e descentralização do poder, que permite o desenvolvimento do feudalismo. $O$ retalhamento do território em feudos estende-se por todo o continente europeu, acompanhando a expansão dos reinos bárbaros. A consolidação do poder da Igreja Católica é a característica fundamental desse período de subordinação a razão à fé (expoentes deste pensamento foram Agostinho de Hipona (século V) e Tomás de Aquino (século XIII) (LE GOFF, 1989).
}

Temporalis, Brasília (DF), ano 18, n. 35, jan./jun. 2018. 


\section{temporolis

A ressalva dos estudiosos deste período, segundo Martinelli (2004), entretanto, é que mesmo nesta época, a pauperização das famílias camponesas era um fenômeno excepcional, concentrando-se nas cidades, pois a estrutura agrária da sociedade ameaçada pelo aparecimento do capitalismo concorrencial foi paulatinamente substituída pela massa de camponeses lançada à pobreza, no urbano. Constituíram-se com o desenvolvimento do capitalismo do século XVIII, como um dos maiores fenômenos das sociedades modernas.

O pauperismo, no século XVIII, com a Revolução Industrial Inglesa, passa a ser objeto de estudo dos pesquisadores sociais como um novo fenômeno, uma nova pobreza. À época, constatou-se que a pauperização da força de trabalho estava diretamente relacionada à capacidade de produção da sociedade industrial, ainda sob o estágio industrialconcorrencial. Qual a necessidade da breve recuperação histórica sobre pobreza para os dias atuais?

Entendemos que o neoconservadorismo progressista, absorvida nos direcionamentos do combate à pobreza na América Latina, nas últimas décadas, incute valores da doutrina liberal beneficência (grifos nossos). Tem seu fundamento na caridade religiosa e é inspirado nos "[...] quatro modos de promoção humana: assistência, ensino, participação e transformação" (MARTINELLI, 2004, p. 31).

Cabe esclarecer que o neoconservadorismo progressista, presente na igreja também influenciou a implementação das políticas de combate à pobreza.

Esta corrente [o neoconservadorismo progressista] busca reconstruir a cristandade com um novo espírito, com novos temas e valores progressistas [...] não questionando a estrutura específica da cristandade, mas apenas dandoIhe um novo conteúdo e uma nova função social, para renovar assim a vida eclesial institucional [...] Integra em suas estruturas sociais, ideológicas e teológicas todos os temas, conteúdos e valores da igreja popular (por exemplo: análise da realidade sócio-política, libertação, justiça, solidariedade), mas mantém como inquestionável a legitimação do poder político e social dominante para assegurar a presença e influência da Igreja no conjunto da sociedade. (RICHARD, 1981, p. 81 apud Ibid., p. 31-32).

Em relação à expressão "questão social" ela foi tratada, historicamente, sob o ângulo do poder, vista como uma ameaça que a luta de classes - em especial, o protagonismo da classe operária representava à ordem instituída. Entretanto, os processos sociais que ela traduz encontram-se no centro da análise de Marx sobre a sociedade capitalista.

Nas palavras de lamamoto (2003, p. 28), a expressão "questão social" surge, na "tensão entre a produção de desigualdade e produção da rebeldia e da resistência". Para a autora:

[...] a questão social não é senão as expressões do processo de formação e desenvolvimento da classe operária e de seu ingresso no cenário político da sociedade, exigindo seu reconhecimento como classe por parte do empresariado e do Estado. É a manifestação, no cotidiano da vida social, da contradição entre o proletariado e a burguesia (IAMAMOTO, 2003, p. 77).

Temporalis, Brasília (DF), ano 18, n. 35, jan./jun. 2018. 


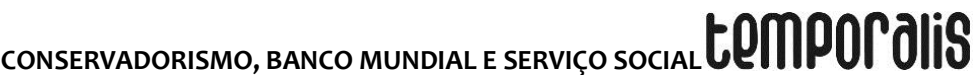

A expressão "questão social" historicamente é objeto do Serviço Social, desde sua gênese nos marcos da Europa Ocidental no século XIX até os países americanos quando migrou ao longo do século XX. As expressões da "questão social", como objeto de análise e intervenção profissional do Serviço Social é elemento fulcraz, conforme a convocação da Associação Brasileira de Ensino e Pesquisa (ABEPSS) e expresso nas Diretrizes gerais para o Curso de Serviço Social, estabelecido (ASSOCIAÇÃO BRASILEIRA DE ENSINO E PESQUISA EM SERVIÇO SOCIAL, 1996). "[...] nos meios profissionais e acadêmicos do Serviço Social brasileiro, o consenso segundo o qual a 'questão social' deve constituir uma verdadeira pedra de toque nas concepções teórico-práticas do Serviço Social” (NETTO, 2010, p. 11).

Entre seus estudiosos imprime-se certo consenso de que o pauperismo iniciado ao final do século XIX como processo de industrialização e usurpação da vida social foi abordado pelo pensamento social da época como um novo fenômeno social. Considerado como uma nova pobreza estava intrínseca ao modo de produção e reprodução das relações sociais.

O cenário é conturbado por um movimento golpista de impechment do poder executivo em abril de 2016 e da autocracia burguesa brasileira à frente de uma orquestração da defesa intransigente contra a perda histórica de privilégios assentados na relação social alienada que monopoliza os frutos do trabalho coletivo. O governo golpista do (ex) vicepresidente Michel Temer (2016-atual), tem no espectro um conservadorismo sem precedentes de extrema-direita do capital. Reconhecemos forças reacionárias apoiando este processo.

$\mathrm{Na}$ arena política brasileira do golpe de Estado, temos em 2018 um ano crucial com eleições em vários países da região: Brasil, México, Colômbia e Costa Rica, entre outros, o investimento sofrerá pressões para baixo até que seja conhecido o desenlace, especialmente no Brasil e México. "Um processo eleitoral com maior nível de conflito gera mais incerteza, obviamente, afirmou a jornalistas o diretor do FMI Alejandro Werner, que comanda as análises para a América Latina. Recentemente, o órgão elevou a expectativa de crescimento do Brasil, de 1,5\% para 1,9\% em 2018" (INCERTEZA..., 2018). Reforça, ainda, sobre a confirmação da condenação do ex-presidente Luiz Inácio Lula da Silva, e o impacto disso na eleição "[...] um processo eleitoral que poderia ter um maior nível de conflitos também gera incertezas e poderia adiar o investimento. Mas não estamos usando este cenário no momento" (É MELHOR..., 2018). "Isso não significa que sejam antevistos desequilíbrios macroeconômicos em função dos resultados, mas sim que o investimento irá parar até que tudo se esclareça" (FARIZA, 2018, não paginada).

Em relação ao caso brasileiro, a preocupação dos investidores sobrecai na reversão de uma agenda reformista em andamento, afinada com o impopular projeto neoliberal de alterações no sistema previdenciário e a potencial reversão na recuperação das finanças públicas.

Numa cerimônia na Casa Civil, na Presidência da República, do governo federal golpista de Temer, em março de 2018, o Banco Mundial elabora novos relatórios com diagnósticos importantes para o Brasil: "Competências e Empregos - Uma agenda para a juventude" e "Emprego e Crescimento - A Agenda da Produtividade". Os economistas da instituição

Temporalis, Brasília (DF), ano 18, n. 35, jan./jun. 2018. 


\section{temporalis}

analisam o que está por trás do cenário econômico e social do País e propõe prioridades e diretrizes a serem adotadas que aponte para uma análise dos gastos de governo com vias a identificar alternativas para diminuir o déficit fiscal a um nível sustentável, além de concretizar os ganhos sociais atingidos em anos anteriores (BANCO MUNDIAL, 2018a).

A aposta de ambos os relatórios está na direção das reformas sociais. O primeiro relatório, Competências e Empregos, aponta um acentuado contraste no progresso que o país obteve na área social nas últimas décadas. Confere que houve baixa efetividade das instituições sociais e econômicas no combate à exclusão social (sic). "Este relatório é a segunda parte de um programa de serviços analíticos e consultoria do Banco Mundial para o Governo do Brasil concentrado em políticas relativas a competências e empregos, e enfatiza a produtividade" (BANCO MUNDIAL, 2018a, p.11) e acrescenta:

O relatório argumenta que, contra o pano de fundo do rápido envelhecimento da população, há uma renovada urgência em melhorar os resultados das políticas públicas focadas em competências e empregos dos jovens. O Brasil simplesmente não pode se dar ao luxo de envelhecer antes de alcançar o status de país de alta renda. O ritmo do envelhecimento da população implica que o Brasil não pode mais se basear na acumulação de fatores produtivos (BANCO MUNDIAL, 2018a, p. 12).

O segundo relatório, Emprego e Crescimento, destaca alguns dos aspectos que podem estar por trás do cenário de baixa produtividade no Brasil e apresenta possíveis fatores que impulsionariam o crescimento da renda e do emprego. Seu objetivo coaduna com o incentivo nacional do Estado em políticas governamentais de aceleração do crescimento da produtividade em "[...] direção à prosperidade compartilhada" (BANCO MUNDIAL, 2018b, p. 15). Acredita e impõe a análise sobre a baixa e estagnada produtividade no Brasil alegando que no "[...] Brasil existe um sistema econômico que desincentiva a concorrência e estimula a ineficiência e a alocação inadequada de recursos. As empresas brasileiras operam em um ambiente de custos elevados" (BANCO MUNDIAL, 2018b, p.11).

\footnotetext{
A produtividade pode aumentar drasticamente com a introdução de um novo conjunto de políticas voltadas para abrir os mercados brasileiros à concorrência, reduzir os custos para fazer negócios, eliminar as distorções induzidas pelo governo e canalizar as despesas públicas para o apoio à inovação e aos ganhos de eficiência (BANCO MUNDIAL, 2018b, p.11).
}

O ministro da Casa Civil Eliseu Padilha afirma no lançamento do Relatório que "[...] o atual governo sempre entendeu que o País precisa avançar em reformas que impulsionem a produtividade e isso tem sido prioridade na agenda [...]" (PADILHA, 2018 apud AZEVEDO, 2018, não paginado), destacando as mudanças na legislação trabalhista, na reforma do sistema de ensino, no aprimoramento do sistema tributário e na consolidação fiscal. "O objetivo deste relatório é incentivar um debate nacional sobre o papel que as políticas governamentais podem desempenhar na aceleração do crescimento da produtividade em direção à prosperidade compartilhada" (BANCO MUNDIAL, 2018b, p. 15).

O diagnóstico do Banco Mundial assegura que para melhorar o cenário é preciso: abrir mercados e reformar as regulamentações empresariais para aumentar a concorrência; promover reforma tributária; acabar com subsídios ineficazes e destinar esses recursos 


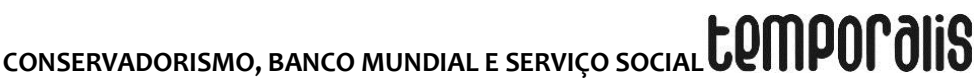

para a inovação e apoio aos trabalhadores; e definir objetivos claros para promover a produtividade, melhorar a coordenação das políticas públicas e avaliar seus resultados.

O relatório Um ajuste justo: análise da eficiência e equidade do gasto público no Brasil (BANCO MUNDIAL, 2017) já desenhava um ajuste justo que apontou as contas fiscais do Brasil para num alinhamento com a proposta sustentável, ao mesmo tempo, que intenciona tratar da extrema pobreza como um grande desafio.

Como usualmente nas orientações do Banco Mundial, assim como do Fundo Monetário Internacional (FMI), estamos nos deparando com uma forte influência hegemônica de manipulação forçada a impor a sociedade brasileira a reformada previdência, ferindo os direitos sociais já conquistados.

Dentre as recomendações do Banco Mundial neste relatório destacamos:

- Recomendações para aperfeiçoar as políticas macroeconômicas.

- Implementar o ajuste fiscal planejado por meio de cortes permanentes nos gastos.

- Reformar o sistema de aposentadoria.

- Desvincular os pisos dos benefícios do salário mínimo.

- Deslocar mais recursos para as transferências que chegam aos pobres, incluindo o Bolsa Família.

- Definir a indicação do presidente do BCB e dos membros do COPOM com termo fixo.

- Diminuir as políticas de apoio industrial voltadas a setores e localidades específicas, inclusive incentivos fiscais.

- Avaliar os programas existentes de apoio industrial .

- Reforçar os procedimentos de denúncia e leniência.

- Restringir as indicações políticas, principalmente nas empresas estatais.

Entendemos que a investida do Banco Mundial movidas pelos Relatórios, além dos empréstimos e assessoria técnica que o Banco promove, é preservada por um conservadorismo que se apresenta na ação política de direita (e de extrema-direita). A compreensão é de que não é algo do passado que se exibe no cenário de uma democracia. Percebemos como uma expressão da luta de classes e que, portanto, expressa movimentos contra-revolucionários. Nestes termos, não é como nos faz crer como algo surpreendentemente novo e aparentemente sem um motivo real.

Vejamos como uma expressão que manifesta na aparência a luta entre interesses antagônicos que formam a sociabilidade burguesa. Imputa uma estratégia de uma ação política da direita cujo impacto orienta a amenização da luta de classes para que fosse possível um conjunto de reformas de baixa intensidade no longo prazo (IASI, 2015).

Este panorama pulveriza os mais diversos espaços da vida social como na cultura, nos imaginários e suas crenças na construção de valores que integram o mesmo ideário como um pensamento único e natural, portanto a-histórica. Supõe, nesta esfera, que não há outra alternativa de modo de vida e organização do trabalho. 


\section{temporalis}

Desta forma, compartilharmos, portanto, da ideia de que a "questão social" não é um fenômeno novo, já que a "questão social" é constitutiva da dinâmica do capital e do tratamento na relação entre a acumulação do capital e seus impactos na força viva de trabalho. Posto isto, a resolução dos problemas torna-se uma falácia travestida de única possibilidade no enfrentamento da pobreza, desqualificando a luta de classes e ampliando a desigualdade social.

Nesta conjuntura, o Serviço Social enfrenta o desafio de aproximar-se dos movimentos sociais organizados no horizonte da organização da classe trabalhadora para a contraordem burguesa para exigir a universalização dos direitos da estrutura política e a desnaturalização da "questão social”.

O projeto ético político do Serviço Social surge denunciando o conservadorismo que assolava a profissão desde a gênese da sua fundação. Conservadorismo esse que impedia que as intervenções profissionais para com os trabalhadores pudessem ser realizadas de uma forma clara, efetiva, livre de preconceitos e enraizada nos moldes éticos de uma profissão que enxergasse a totalidade e não que ficasse firmada em moldes religiosos e gerisse sua prática de uma forma imediatista e filantrópica.

\section{CONCLUSÃO}

Vive-se numa época da qual existe uma regressão dos direitos e destruição do legado de conquistas históricas dos trabalhadores em nome da defesa do mercado e do capital, cujo reino pretende-se à acumulação cada vez maior com base na propriedade dos meios de produção e do trabalho alheio.

Um contexto sócio-histórico refratário aos influxos democráticos exige, contraditoriamente, a construção de uma nova forma de fazer política - que consolide a formação e o trabalho dos assistentes sociais- capaz de acumular forças na construção de novas relações entre o Estado e a sociedade civil que reduzam o fosso entre o desenvolvimento econômico e o desenvolvimento social, entre o desenvolvimento das forças produtivas e das relações sociais.

Requer, portanto, uma concepção de cidadania e de democracia para além dos marcos liberais, articulados à organização da classe trabalhadora. A cidadania entendida, aqui, como capacidade de todos os indivíduos, no caso de uma democracia efetiva, de se apropriarem dos bens socialmente produzidos, de atualizarem as potencialidades de realização humana, abertas pela vida social em cada contexto historicamente determinado. Como sustenta Coutinho (2000) é nessa concepção abrangente que a democracia inclui a socialização da economia, da política e da cultura na direção da emancipação humana.

Aqui destacamos que partilhamos da compreensão da emancipação humana alicerçada na distribuição da riqueza socialmente produzida e não sob o hedge do reformismo das políticas púbicas com a universalização dos direitos sociais, ainda que este seja o horizonte da democracia, justiça social e cidadania que queremos consolidar na autocracia burguesa brasileira.

Temporalis, Brasília (DF), ano 18, n. 35, jan./jun. 2018. 


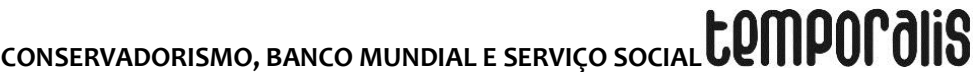

Como apresentado nos tópicos anteriores, estamos num contexto no qual, o sistema capitalista visando reergue-se de uma crise estrutural constrói mecanismos que são disseminados pelos intelectuais orgânicos do capital, refletindo assim, em grandes transformações no mundo do trabalho; assim como, na vida social de cada sujeito. Não estando, assim, o assistente social fora desse processo.

O assistente social, compõe o conjunto de trabalhadores assalariados que sofrem cotidianamente com o processo de precarização, flexibilização do trabalho, sucateamento dos serviços públicos, através de políticas focalizadas e paliativas, e seletivas contradizendo a universalização de direitos sociais ao recrudecerem à benefícios articulados aos ajustes fiscais impostos pelos governos e acenando para a retirada da controle social e participação popular - conquistada à duras penas no processo de redemocratização brasileira.

Na contramão dos dogmas oficiais, segmentos dos assistentes sociais têm buscado um compromisso efetivo com os interesses públicos e articulação aos movimentos organizados da classe trabalhadora no horizonte da emancipação humana. Concebemos que o Serviço Social voltado à defesa dos direitos de cidadania e dos valores democráticos, na perspectiva da liberdade, da equidade e da justiça social rebate, com força, o conservadorismo de novo tipo, recorrendo à história com enfoque críticoanalítico como um instrumento crucial associado a análise dos fundamentos do conservadorismo clássico.

Entendemos aqui que a defesa dos direitos sociais não se esgota nela mesma, mas que reflete como um dos elementos enfáticos à democracia não liberal. O que queremos dizer é que esta defesa não é um fim em si mesmo, mas um dos motes importantes na direção de outra ordem societária, resguardando os sentidos tratados da defesa de direitos sociais com vistas às reformas sociais que implica a manutenção da ordem capitalista com uma roupagem mais humana e a retomada do conservadorismo na profissão.

\section{REFERÊNCIAS}

ASSOCIAÇÃO BRASILEIRA DE ENSINO E PESQUISA EM SERVIÇO SOCIAL. Diretrizes gerais para o curso de Serviço Social (Com base no Currículo Mínimo aprovado em Assembléia Geral Extraordinária de 8 de novembro de 1996). Rio de Janeiro, 1996.

AZEVEDO, Alessandra. Padilha: país precisa avançar em reformas para melhorar produtividade. Correio Brasiliense, Brasília (DF), 7 mar. 2018. Disponível em: $<$ https://www.correiobraziliense.com.br/app/noticia/economia/2018/03/07/internas_econ omia,664436/padilha-pais-precisa-avancar-em-reformas-para-melhorarprodutividade.shtml>. Acesso em: 18 abril de 2018.

BANCO MUNDIAL. Estratégia de assistência ao país: EAP para 2004-2007. Washington (DC), 2003.

BANCO MUNDIAL. Erradicar a pobreza extrema: 2030: promover a prosperidade compartilhada. Relatório de Desenvolvimento Mundial, Washington (DC), 2013. 


\section{temporalis}

<https://openknowledge.worldbank.

org/bitstream/handle/10986/16091/9780821399422PT.pdf>. Acesso em: 15 abril de 2018.

BANCO MUNDIAL. Um ajuste justo: análise da eficiência e equidade do Gasto Público no Brasil. Washington (DC), 2017. Disponível em:

<http://www.worldbank.org/pt/country/brazil/publication/brazil-expenditure-reviewreport>. Acesso em: 12 dez. 2017.

BANCO MUNDIAL. Competências e empregos: uma agenda para a juventude e Emprego e Crescimento: A Agenda da Produtividade. Síntese de constatações, conclusões e recomendações de políticas. Washington (DC), 2018a. Disponível em:

$<$ http://documents.worldbank.org/curated/en/953891520403854615/pdf/123968-WPPUBLIC-PORTUGUESE-P156683-

competenciaseEmpregosUmaAgendaparaa Juventude.pdf>. Acesso em: 7 abr. 2018.

BANCO MUNDIAL. Emprego e Crescimento. A Agenda da Produtividade. Washington (DC): World Bank Group, $1^{\circ}$ mar. 2018b. Disponível em: $<$ http://documents.worldbank.org/curated/en/203811520404312395/pdf/123969-WPPUBLIC-PORTUGUESE-P162670-EmpregoeCrescimentoAAgendadaProdutividade.pdf >. Acesso em: 7 abr. 2018.

BONENTE, Bianca Imbiriba; CORRÊA, Hugo Figueira. Desenvolvimento sem "ismos": uma crítica ao novo-desenvolvimentismo a partir dos Grundrisse de Marx. Outubro, n. 23, $1^{\circ}$ semestre de 2015.

BONENTE, Bianca Imbiriba. Desenvolvimento em Marx e na teoria econômica: por uma crítica negativa do desenvolvimento capitalista. 2011. Tese (Doutorado em Economia)Programa de Pós-graduação em Economia, Universidade Federal Fluminense, Niterói, 2011.

BORON, Atílio. A sociedade civil depois do dilúvio neoliberal. In: SADER, Emir; GENTILI, Pablo. Pós-neoliberalismo: as políticas sociais e o estado democrático. Rio de Janeiro: Paz e Terra, 1995.

CARCANHOLO, Marcelo Dias. Conteúdo e forma da crise atual do capitalismo: lógica, contradições e possibilidades. Crítica e Sociedade: revista de cultura política, Uberlândia, v.1, n.3, Edição Especial: Dossiê: A crise atual do capitalismo, dez. 2011.

CASTELO, Rodrigo. O novo desenvolvimentismo e a decadência ideológica do pensamento econômico brasileiro. Serviço Social e Sociedade, São Paulo, n. 112, p. 613636, out./dez. 2012.

CHESNAIS, François. A mundialização do capital. São Paulo: Xamã, 1996.

COUTINHO, Carlos. N. Contra a corrente: ensaios sobre democracia e socialismo. São Paulo: Cortez, 2000.

Temporalis, Brasília (DF), ano 18, n. 35, jan./jun. 2018. 


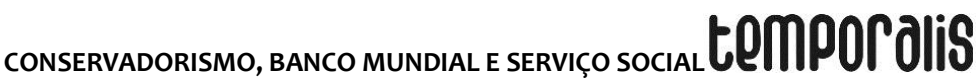

FARIZA, Ignacio. $1 \%$ da população mundial concentra metade de toda a riqueza do planeta. Desigualdade aumentou desde da crise de 2008 e chega ao ápice em 2015. El País on line, México, 17 out. 2015. Disponível em:

<https://brasil.elpais.com/brasil/2015/10/13/economia/1444760736_267255.html>. Acesso em: 23 maio 2016 .

FARIZA, Ignacio. À espera de eleições. América Latina se equilibra em incertezas para recuperar brio econômico. Eleições no Brasil e México ditam a cadência de uma região com grandes disparidades de crescimento. El País on line, México, 27 fev. 2018. Disponível em: <https://brasil.elpais.com/brasil/2018/02/23/internacional/1519384144_093464.html>. Acesso em: 28 mar. 2018.

INCERTEZA com eleições deve impactar crescimento do Brasil, diz FMI. Folhapress, São Paulo, 25 jan. 2018. Disponível em:

<https://www.folhape.com.br/economia/economia/economia/2018/01/25/NWS,56802,10,5 50,ECONOMIA,2373-INCERTEZA-COM-ELEICOES-DEVE-IMPACTAR-CRESCIMENTO-BRASILDIZ-FMI.aspx>. Acesso em: 16 abr. 2018.

IAMAMOTO, Marilda Villela. Mundialização do capital, questão social e Serviço Social no Brasil. Em pauta, Rio de Janeiro, v. 1, n. 21, p. 117-139, 2008.

IAMAMOTO, Marilda Villela. Serviço Social em tempo de capital fetiche: capital financeiro, trabalho e questão social. 4. ed. São Paulo: Cortez, 2007.

IAMAMOTO, Marilda. As dimensões ético-politicas e teórico-metodológicas no Serviço Social contemporâneo. In: MOTA, Ana Elizabete et al. (Org.). Serviço Social e Saúde: formação e trabalho profissional. São Paulo: Cortez; Brasília (DF): Organização PanAmericana da Saúde; Organização Mundial da Saúde; Ministério da Saúde, 2006. p.161196.

IAMAMOTO, Marilda Villela. O Serviço Social na contemporaneidade: trabalho e formação profissional. 6. ed. São Paulo: Cortez, 2003.

IAMAMOTO, Marilda Villela. A questão social no capitalismo. Temporalis, Brasília (DF): Associação Brasileira de Ensino e Pesquisa em Serviço Social, n. 3, 2001.

IAMAMOTO, Marilda Villela. O Serviço Social na contemporaneidade: trabalho e formação profissional. 2. Ed. São Paulo: Cortez, 1999.

IASI, Mauro Luis. De Onde Vem o Conservadorismo? Blog Boitempo, São Paulo, 15 abr. 2015. Disponível em: <https://blogdaboitempo.com.br/2015/04/15/de-onde-vem-oconservadorismo/>. Acesso em: 8 out. 2017. 


\section{temporalis}

OLIVEIRA, ANA CRISTINA OLIVEIRA DE

"É MELHOR que se faça bem do que se faça rápido", diz FMI sobre reforma da Previdência. Jornal do Brasil on line, Rio de Janeiro, 25 jan. 2018. Disponível em: <http://m.jb.com.br/economia/noticias/2018/01/25/e-melhor-que-se-faca-bem-do-que-sefaca-rapido-diz-fmi-sobre-reforma-da-previdencia/ >Acesso em: 17 mar. 2018.

LE GOFF, Jacques. Os intelectuais na idade média. São Paulo: Brasiliense, 1989.

LEITE, Leonardo de Magalhães. Imperialismo, Dependência e Subimperialismo: mapeando as relações categoriais. Revista Espacio Crítico, n. 22, 2015.

LUCE, Mathias Seibel. A teoria do subimperialismo em Ruy Mauro Marini: contradições do capitalismo dependente e a questão do padrão de reprodução do capital. 2011. Tese (Doutorado em História)-Programa de Pós-graduação em História, Universidade Federal do Rio Grande do Sul, Porto Alegre, 2011.

Luce, Mathias Seibel. A superexploração da força de trabalho no Brasil. REVISTA Soc. Bras. Economia Política, São Paulo, n. 32, p. 119-141, jun.2012.

LUCE, Mathias Seibel. Teoria Marxista da Dependência: problemas e categorias - uma visão histórica. São Paulo: Expressão Popular, 2018.

MARTINELLI, Rosana de Carvalho. A política de combate à pobreza e as agências multilaterais: um estudo comparativo entre o Brasil e o México nas décadas de 80 e 90. 2004. 409f. Tese (Doutorado em Sociologia Política)-Programa de Pós-Graduação em Sociologia Política, Universidade Federal de Santa Catarina, Florianópolis, 2004.

MARINI, Ruy Mauro. Dialética da dependência. In: SADER, Emir. Antologia de Ruy Mauro Marini. Petrópolis: Vozes, 2000.

MARINI, Ruy Mauro. "Sobre a dialética da dependência”. In: TRASPADINI, R.; STEDILE, J. P. (Orgs.). Ruy Mauro Marini: vida e obra. São Paulo: Expressão Popular, 2005.

MARINI, Ruy Mauro. O ciclo do capital na economia dependente. In: FERREIRA, Carla; OSORIO, Jaime; LUCE, Mathias. Padrão de reprodução do capital: contribuições da Teoria Marxista da Dependência. São Paulo: Boitempo, 2012.

MARTINS, U. A Celac desenha uma nova realidade geopolítica na América Latina.

Vermelho, São Paulo, 3 fev. 2014. Disponível em:

$<$ http://www.vermelho.org.br/coluna.php?id_coluna_texto $=5688 \&$ id coluna $=35>$. Acesso em: 8 abr. 2018.

MARX, K. A lei geral da acumulação capitalista. In: MARX, K. O Capital: crítica da economia política. São Paulo: Nova Cultural, 1996.

MÉSZÁROS, István. Para além do capital rumo a uma teoria da Transição. Tradução Paulo Cezar Castanheira, Sérgio Lessa. 1. ed. ver. São Paulo: Boitempo, 2011. 


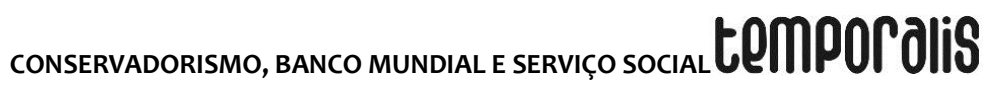

NEVES, L. M. W. A nova pedagogia da hegemonia: estratégias da burguesia brasileira para educar o consenso na atualidade. São Paulo: Xamã, 2005.

NETTO, Leila Escorsim. O conservadorismo clássico: elementos de caracterização e crítica. Cortez: São Paulo, 2011.

NETTO, José Paulo. Prefácio. In: CORLETTO, Alejandra Pastorini. A categoria “questão social" em debate. 3. ed. São Paulo: Cortez, 2010. p. 11-17. (Coleção questões da nossa época).

ORGANIZAÇÃO PARA A COOPERAÇÃO E DESENVOLVIMENTO ECONÔMICO. Relatórios Econômicos OCDE BRASIL 2018: construindo um Brasil mais próspero e mais produtivo Brasília, 28 fev. 2018. Disponível em: <https://www.oecd.org/eco/surveys/Construindo-umBrasil-mais-prospero-e-mais-produtivo-OCDE-relatorios-economicos-2018.pdf $>$. Acesso em: 26 fev. 2018.

OLIVEIRA, Ana Cristina Oliveira de. Os Porta-Vozes do Capital Contemporâneo Mundializado: "Combate à pobreza" e o neoliberalismo de terceira via. In: ENCONTRO INTERNACIONAL DE POLÍTICA SOCIAL, 1.; ENCONTRO NACIONAL DE POLÍTICA SOCIAL, 8., 2013, Vitória. In: Encontro Nacional de Política Social, 8., 2013, Vitória. Anais... Vitória, 2013.

OLIVEIRA, Ana Cristina Oliveira de. Crítica à nova sociabilidade do capital: por um "capital mais humano". 2012. 611f. Tese (Doutorado em Serviço Social)-Programa de PósGraduação em Serviço Social da Faculdade de Serviço Social da Universidade do Estado do Rio de Janeiro, Rio de Janeiro, 2012.

OSORIO, Jaime. Dependência e superexploração. In: Carlos Eduardo Martins e Adrián Sotelo Valencia (Orgs.). A América Latina e os desafios da globalização. Ensaios dedicados a Ruy Mauro Marini. São Paulo: Boitempo, 2009.

OSORIO, Jaime. Fundamentos da superexploração. In: Niemeyer Almeida Filho (Org.). Desenvolvimento e dependência. Brasília (DF): Instituto de Pesquisa Econômica Aplicada, 2013.

PEREIRA, João Márcio Mendes. O Banco Mundial como ator político, intelectual e financeiro: (1944-2008). Rio de Janeiro: Civilização Brasileira, 2010.

PETRAS, J. Império e políticas revolucionárias na América Latina. São Paulo: Xamã, 2002.

SAMPAIO JÚNIOR, Plínio de Arruda. Desenvolvimentismo e neodesenvolvimentismo: tragédia e farsa. Serviço Social e Sociedade, São Paulo, n. 112, out./dez. 2012.

TAVARES, M. da Conceição; MELIN, Luiz Eduardo. Mitos globais e fatores regionais: a nova desordem internacional. In: FIORI, José Luiz et al. (Orgs.). Globalização: o fato e o mito. Rio de Janeiro: Universidade Estadual do Rio de Janeiro, 1998.

YAZBEK, M. C. Classes subalternas e assistência social. São Paulo: Cortez, 1993.

Temporalis, Brasília (DF), ano 18, n. 35, jan./jun. 2018. 


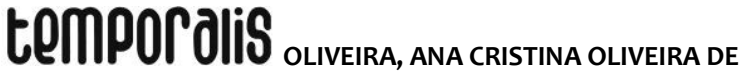

Temporalis, Brasília (DF), ano 18, n. 35, jan./jun. 2018. 